\title{
The Behaviors of Multi-institute scientific organizations in nanotechnology
}

\author{
R. M. Pei ${ }^{1}$, W. $\mathrm{Liu}^{2}$ \\ ${ }^{1}$ Department of Information Research, Library of Chinese Academy of Sciences, Beijing, China \\ ${ }^{2}$ Department of Technology Management, Agriculture Bank of China, Beijing, China \\ (peirm@mail.las.ac.cn,weiliu.cs@gmail.com)
}

\begin{abstract}
The large public scientific organizations - we call in this paper multi-institute scientific organizationsalways play important roles in the national innovation systems, and undertake basic research, applied research, some science frontier research and the research of emerging areas like nanotechnology. To examine the behaviors of these large public scientific organizations is important for monitoring the development of a nation's scientific strategy and evolutionary of science and technology. This paper focuses on five important public scientific organizations in nanotechnology, and compares their scientific behaviors. The results show that although they all develop rapidly in nanotechnology, they have different foci and different collaboration behaviors.
\end{abstract}

Keywords - multi-institute scientific organizations, nanotechnology, bibliometrics

\section{INTRODUCTION}

Large-scale public scientific organizations are primary organizational actor in the scientific world. These organizations typically are largely funded by government, have multiple institutes, cross different scientific fields, and undertake a substantial role in conducting research, especially basic research and strategic technologies of their national governments. Examples of these types of multi-institute scientific organizations (MISOs) are Chinese Academy of Science (CAS) in China, Russian Academy of Sciences (RAS) in Russia, CNRS in France, CNR in Italy, and CSIC in Spain. Despite the strategic role of MISOs, there have been few comparative studies of the approaches represented by these organizations in emerging technologies such as nanotechnology. In this paper we examine the approaches used by MISOs based on their nanotechnology publication patterns, including their disciplinary emphasis and collaborative networks. We posit that the approaches used by MISOs in nanotechnology research reflect the traditional disciplinary and collaborative strengths of these organizations. This proposition is in contrast with the position that organizations may migrate to new areas of disciplinary and collaborative activity to acquire their share of the new resources available in pursuing new scientific breakthroughs in emerging technologies. The results show that the publications of MISOs increased between 1999 and 2009, the average ratio of each MISO to the respective country is from $18.18 \%$ to $51.06 \%$. We then analyze the evolution of each MISO research pattern from 1991-1992 to $1999-2000$ to 2007-2008 from the quantity and quality of the publication, the discipline, the collaboration patterns.

\section{LITERATURE REVIEW}

The literatures on research institutes similar to MISO focus on assessment and evaluation of research institutes. Some of these studies use particular methodologies and indicators [1-9].For example, Bassecoulard \& Zitt [] tested convergence of pure citation-built specialities on SCI/CMCI journals at the subfield level and explored the interest and the limit of the approach for upper levels of aggregation. Coccia [1] provided a new model to measure and evaluate research performance of public research institutes and applied the approach to 108 public research institutes belonging to the Italian National Research Council (INRC).Hayati \& Ebrahimy []ㅡ examined the correlations between quality and quantity in scientific production in three groups - universities, research institutes and other organizations. The results revealed that the correlation in research insititute was stronger than the other two groups. Hyvarinen [8] offers new evaluation tools to analyze talented behavior effects of Tekes funding for research institutes and universities in Finland. Lee[2] evaluated the research performance of the Institute of Molecular and Cell Biology (IMCB) in Singapore. Modrego-Rico et al. [9] measured the performance and its determinants of Technology institutes (TIs) in Spanish. Vinkler [10] used the weighted scientometric indicators to yield a General Performance Index (GPI) which were used to assess the research insitutes' performance. Vinkler [4] provided a composite indicator by composing the qualitative and quantitative scientometric indicators for the assessment of publications of research teams or institutes. Yawson et al. [7] developed a performance measurement framework for the Food Research Institute (FRI) and the application of the Balanced Score Card (BSC) at institutional level.

Others examine interrelationships of industry and research institutes [11]. Also in relation to commercialization activities of MISOs, there have been studies of patent activities of research institutes[12]. The results of Guan [13]'s research indicated that the collaboration between industry and research institutes / universities was related to the technology novelty of industrial innovation. And in that paper the major barriers to successful collaboration had also been addressed. Lee [12]'s work used a binary choice model to investigate factors affecting patent licensing, and double-bounded tobit and duration models to investigate factors affecting 
patent life. The results showed that research collaboration had positive effects on both patent licensing and patent life, and testified the effects of several factors from the aspect of research team institution, geographical localization and age on patent licensing and patent life.

There is a third group of studies of MISOs that develop case profiles and studies of particular MISOs. $[14, \underline{15}]$, and series of studies on a specific institute [1619]. Nederhof [15] wentdown to the level of research groups and individual to profile their researh types and to monitor developments in research related to societal needs and problems based on the publications in journals covered by the SSCI. Thijs [19]developed a model to assign institutes to one of the 8 different groups according to their research fileds, and thus enhanced the comparability of research performance of institutes. To make the comparison and evaluation of research institutes performance more reasonable, Thijs [16]classified the European research institutes into 8 groups using hierarchical clustering according to their publication profiles. Thijs [18] combined four evaluation principles to introduce a dynamic perspective on institutional research performance of Israel at macro and meso levels. Thijs [17] used the classification model to identify the specialisms of research institution, to create groups of similar institutions and to study the relationship between science fileds and collaboration. The results showed the effect of research profile on the shares of different types of collaboration, investigated the changes on impact and publication strategy over the different types of collaboration and found the preferred partners for each group of the research profile.

Lee [14], using the term government-supported research institutes (GRIs), puts forth several roles for these GRIs. He suggests that an important role of GRIs is to conduct $\mathrm{R} \& \mathrm{D}$ in the areas in which industry is reluctant to invest due to high risk and low profit, and which universities cannot afford to investigate due to limited R\&D capabilities. GRIs can also serve as effective mechanism of implementing government policy to pursue science and technology promotion. GRIs also take a future-oriented, long-term, large-scale research and development orientation in its projects.

Although they play an important role in national R\&D performance, there are few studies of MISOs. Some studies focus on the specific institute [7], but few studies analyze them from a comparative perspective.

\section{METHODOLOGY}

By examining the nano-database of Georgia Tech [20] which is based on the Thomson ISI's Web of Science - SCI via the module Boolean Search Strategy [20], we found that Chinese Academy of Science (abbreviated as "CAS" in the following) makes significant contribution in nano science and technology, as well as Russian Academy of Sciences ("RAS"). These organizations are public, national, and governmentsupported research organizations, their main resources come from the government, as well as from the market; they are multidisciplinary in fundamental research, they try to obtain further knowledge of the natural, social and human development and their aim is to promote technological, economic, social and cultural development; generally, they are multi-region distributed, in other words, their institutes spread throughout the whole country. The similar organizations are the CNRS in France, CNR in Italy, CSIC in Spain ${ }^{1}$. We term this kind of organization Multi-Institutes Scientific Organization ("MISO"). For example, the data from the nano database shows that the publications in their each of these five organizations account for around $20 \%$ overall their country's publications. The publications of RAS accounts for the more than $50 \%$ during the period from 1990 to 2009. That stimulates our interest of looking deeply into this kind of organizations - What are precisely their R\&D performances? What are their discipline interactions? What are their collaboration patterns? How does nanoR\&D allocated inside the organization? In this paper, we choose nanotechnology as our target case because of the emerging and strategic role of nanotechnology and its impressive market values.

Early research has suggested that nanotechnology is a general purpose technology with broad applicability throughout the economy[21].Various studies have shown that nanotechnology continues to demonstrate an overall upward trend in publication and patent activity [22-27] and its subfields [28-30] or in a specific country or region [31-34], the multidisciplinarity and interdisciplinarity of nanotechnology [35-38], visualization of nanotechnology at discipline level [39] and the collaboration level [36, 38], analysis at the individual level [40-42], and other topics [43-45].

Some of these studies employ breakdowns of publications and patents by organization. The problem with this methodology is it mixes single-institution organizations such as most universities with multiinstitution and geographically disparate organizations such as MISOs. This study seeks to address this gap by focusing analysis on the relative nanotechnology S\&T activity of MISOs.

To examine the behaviors of MISOs, we use a measure of the disciplinary specialization that is derived from publications in the Georgia Tech Global nanotechnology database excerpted from the Web of Science (WOS) Science Citation Index (SCI) and that is based on the Institute for Scientific Information's (ISI) journal subject category (SC). SCs have been widely used to represent disciplines, for example in the National Academies Keck Futures Initiative, although they are not without criticism concerning the evolving of SCs and assignment of publications to multiple $\mathrm{SCs}[\underline{35}, \underline{46}]$.

\section{RESULTS}

\footnotetext{
${ }^{1}$ We also examined Fraunhofer in Germany, but with only $2 \%$ share in Germany Nano research and it has quite different organizational and funding structures from the other MISOs.
} 
The basic description of the five MISOs (in Fig. 1) show that the publications of the five MISOs increased as the development of nanotechnology. There are more and more R\&D activities in these organizations. CAS developed rapidly because of the fast development of Chinese nano science and technology. As shown in Fig. 2, the ratio of CAS in China keeps around $20 \%$ with a subtle decrease in recent years. The percentages of all the five MISOs in their countries are around 20\%, except for RAS to Russia with the ratio of around $50 \%$. RAS plays more important role in Russian nanotechnology R\&D than other MISOs in their respective country.

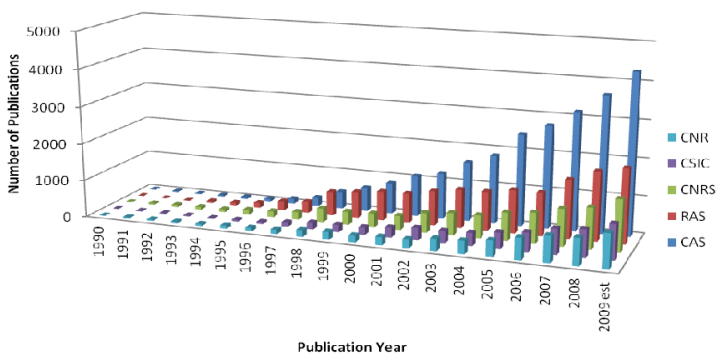

Fig. 1.Publication trends of five MISOs

Note: we standardized the data of 2009 by dividing it by 0.8 to take into account the fact that some publications with dates of 2009 do not appear in the WOS/SCI until 2010 or later due to publication delays.

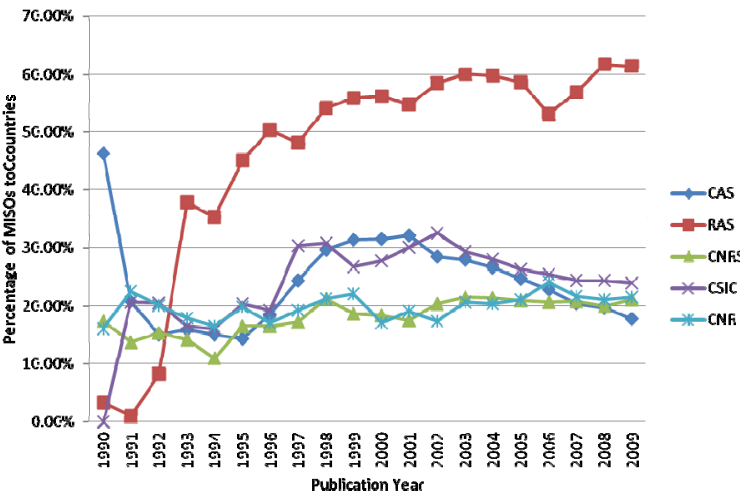

Fig. 2. Ratio of five MISOs publications in (for) respective countries

Fig.3 presents the change over time in publication and citation intensity, with a line connecting the results for the initial period - "1991" (combining 1991 and 1992 publications), the transition period - "1999" (combining 1999 and 2000 publications) and the recent period "2007" (combining 2007 and 2008 publications). The steeper the slope of the line connecting these two points, the greater the increase in quality of the organization's research on this topic. We can see from Fig. 4 that in the early period, CAS, RAS and CNRS developed almost equally rapidly both in quantity and quality. However, the number and quality of CAS publications grow much faster than the other MISOs during the recent period although its ratio in China decreases as time goes by (Fig. 2).
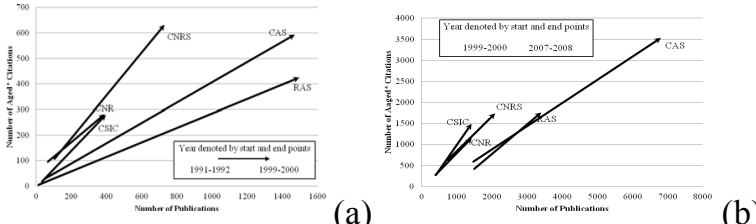

Fig. 3. Number of aged citations of in (a) 1991-1992 and 1999-2000 (b) 1999-2000 and 2007-2008 relative to number of publications

* Aged citations (AC) for affiliationi, calculated as ACi $=\mathrm{Cti} /(\mathrm{Yn}-\mathrm{Yt})$ where $\mathrm{Cti}=$ total number of citations for articles in target year for affiliationi; $\mathrm{Yn}=$ most recent year in dataset $(2010$, part-year); and $\mathrm{Yt}=$ target year. For 1991, Yn-Yt $=18.5$, for 1999, Yn-Yt $=10.5$, and for $2007, \mathrm{Yn}-\mathrm{Yt}=2.5$.

\section{A. The discipline}

The following section is about the disciplines or subject categories on which each MISO focuses. Fig. 4 presents the overlaid science map for each MISO and their top 10 subject categories. CAS and RAS have similar discipline distribution patterns. They focus on Chemistry, Material Sciences and Physics. Except for Chemistry and Material Sciences, CNRS and CSIC also focus on Biomedical Sciences. CNRS has relative broader discipline distribution because its top 10 subject categories are loaded on 5 macro-disciplines - Chemistry, Material Sciences, Biomedical Sciences, Physics and Computer Sciences. CNR seems has the relative narrow discipline spectrum. Its top 10 subject categories are loaded on only two macro-disciplines - Chemistry and Material Sciences.

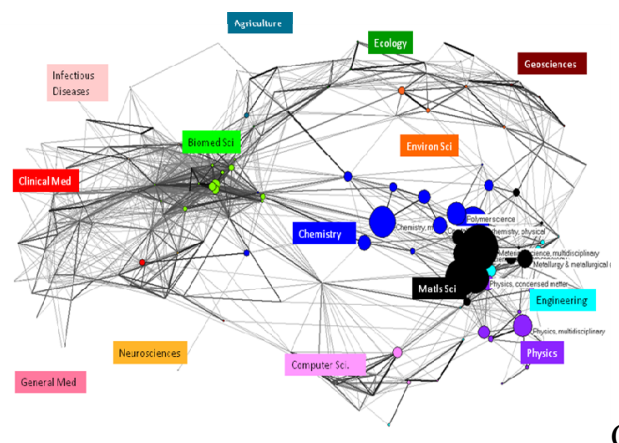

CAS

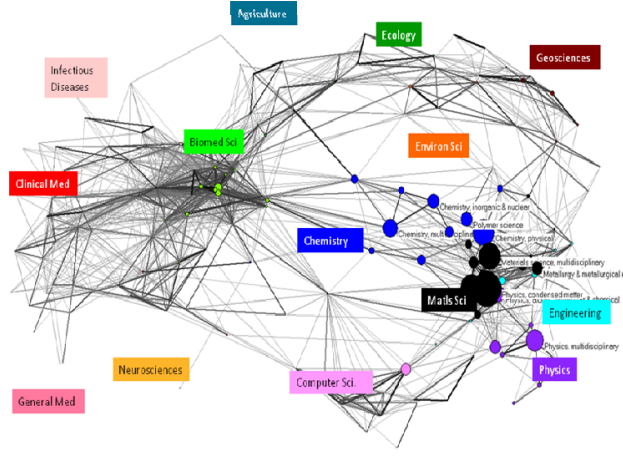

RAS 


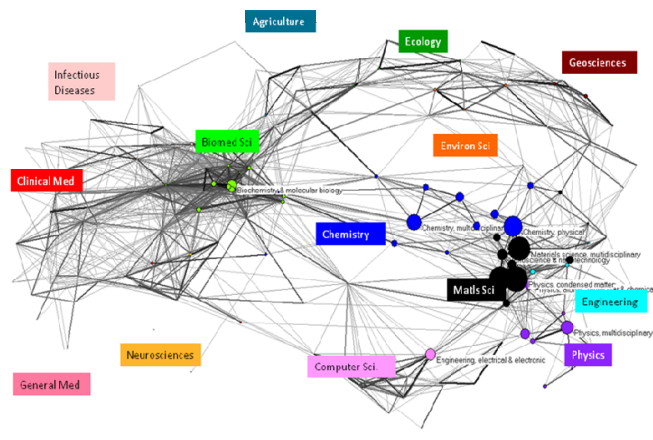

CNRS

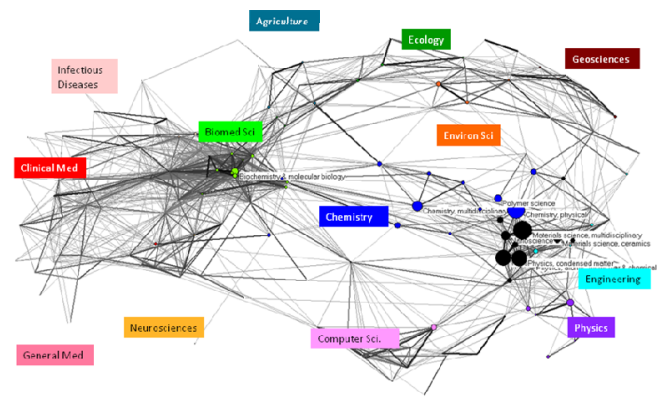

CSIC

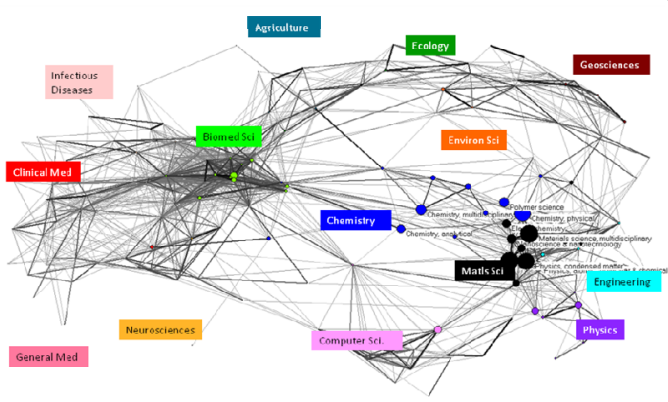

CNR

Fig. 4. Nano publications of five MISOs overlaid on the map of science based on Cited SCs and their top 10 SCs

\section{B. The collaboration behaviors}

Collaboration in research is "a good thing" and that it should be encouraged. At the same time, measuring an institute's research collaboration is an indicator of evaluation (Katz and Martin 1997).

Multiple authorship publications, which frequently referred to as co-authored publications, have been used as basic counting unit to measure collaborative activity (Smith 1958; Subramanyam 1983).

Fig. 5 presents the distribution of number of authors for the nano publications in individual MISO. The results show that most of nano publications in these organizations are multiple authors. Some of them are mega collaborative papers with more than 50 authors in a paper. But the ratio of these mega collaborative papers is small and the mode of the number of authors in each MISO is from 4 to 6 .

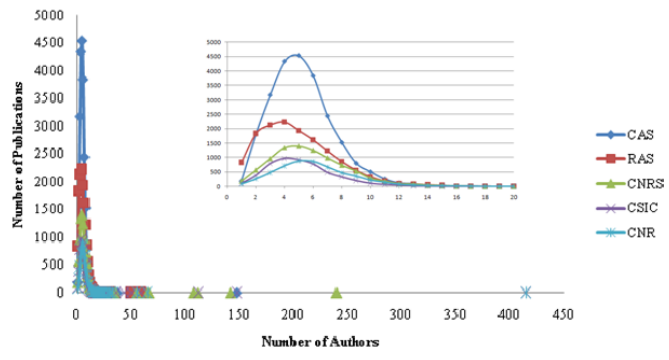

Fig. 5. Distribution of number of authors

Fig.6 delineates the ratio of international collaboration of each MISO. The trend of international collaboration is increasing except RAS having little decrease from 1999 to 2008.Comparing to other MISOs, CAS has the lowest international collaboration in almost every period and its international collaboration grows slowly compared to its growth rate of publications.

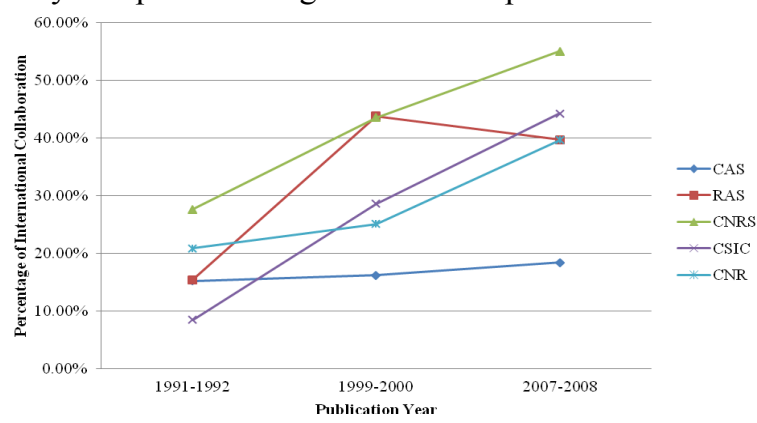

Fig. 6. Ratio of International collaboration of each MISO

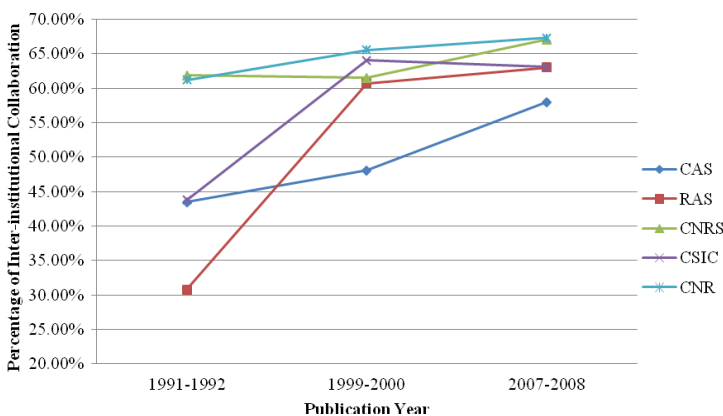

Fig. 7. Ratio of inter-institutional collaboration of each MISO (including foreign research affiliations and domestic affiliations)

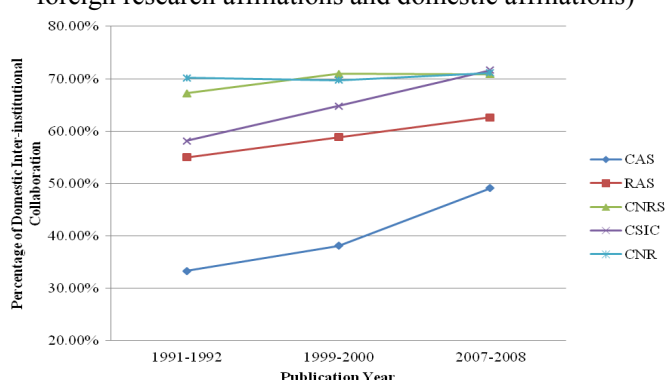

Fig. 8. Ratio of domestic inter-institutional collaboration of each MISO

Go down to the institutional level, as shown in Fig. 7 and 8 , the across-institute collaborations are increasing in five MISOs. Fig. 7 shows the ratio of all the interinstitutional collaborations including foreign institutes 
and domestic institutes. And Figure 9 presents ratio of the inter-institutional collaborations only within their countries. Comparing Fig. 7 and 8, we can see that CAS has the smallest ratios both in the whole inter-institutional collaboration and in the domestic inter-institutional collaboration.

TABLE I-V present the important contributors to each MISO's international co-authored publications. For CAS, the major collaborators are USA, Japan and Germany; for RAS - Germany, USA, France, and UK; for CNRS - Germany, USA, Spain and UK; for CSIC - USA, France, Germany and UK; and for CNR - France, USA, Germany and Spain. The distributions present several characteristics - first of all, their major collaborators are all the prolific countries in nano-field; second, their collaborations present the geographical proximity; third, as time goes by, their collaborators changes a little, but the main contributors keep the same.

TABLE I

IMPORTANT CONTRIBUTORS TO CAS'S INTERNATIONALLY CO-AUTHORED PUBLICATIONS

\begin{tabular}{|c|c|c|c|c|c|c|}
\hline Year & \multicolumn{2}{|c|}{ 1991-1992 } & \multicolumn{2}{|c|}{$1999-2000$} & \multicolumn{2}{|c|}{$2007-2008$} \\
\hline authored papers & \multicolumn{2}{|c|}{7} & \multicolumn{2}{|c|}{237} & \multicolumn{2}{|c|}{1251} \\
\hline $\begin{array}{c}\text { Collaborative } \\
\text { countries }\end{array}$ & $\begin{array}{l}\text { Share } \\
(\%)\end{array}$ & Rank & $\begin{array}{l}\text { Share } \\
(\%)\end{array}$ & Rank & $\begin{array}{c}\text { Share } \\
(\%)\end{array}$ & Rank \\
\hline USA & $28.57 \%$ & 2 & $20.68 \%$ & 2 & $37.81 \%$ & 1 \\
\hline Japan & $14.29 \%$ & 3 & $22.36 \%$ & 1 & $14.47 \%$ & 2 \\
\hline Germany & $28.57 \%$ & 2 & $14.77 \%$ & 3 & $10.71 \%$ & 3 \\
\hline Australia & & & $9.70 \%$ & 4 & $8.79 \%$ & 4 \\
\hline UK & $42.86 \%$ & 1 & $4.64 \%$ & 8 & $6.31 \%$ & 5 \\
\hline
\end{tabular}

TABLE II

IMPORTANT CONTRIBUTORS TO RAS'S INTERNATIONALLY CO-AUTHORED PUBLICATIONS

\begin{tabular}{ccccccc}
\multicolumn{7}{c}{ CO-AUTHORED PUBLICATIONS } \\
\hline $\begin{array}{c}\text { Total } \\
\begin{array}{c}\text { international } \\
\text { co-authored } \\
\text { papers }\end{array}\end{array}$ & \multicolumn{2}{c}{$1991-1992$} & \multicolumn{2}{c}{$1999-2000$} & \multicolumn{2}{c}{$2007-2008$} \\
\hline $\begin{array}{c}\text { Collaborative } \\
\text { countries }\end{array}$ & $\begin{array}{c}\text { Share } \\
(\%)\end{array}$ & Rank & $\begin{array}{c}\text { Share } \\
(\%)\end{array}$ & Rank & $\begin{array}{c}\text { Share } \\
(\%)\end{array}$ & Rank \\
Germany & $50.00 \%$ & 1 & $30.69 \%$ & 1 & $26.50 \%$ & 1 \\
USA & $50.00 \%$ & 1 & $18.47 \%$ & 2 & $19.10 \%$ & 2 \\
France & & & $11.60 \%$ & 4 & $13.32 \%$ & 3 \\
UK & & & $12.82 \%$ & 3 & $6.88 \%$ & 4 \\
Japan & & & $4.43 \%$ & 7 & $6.22 \%$ & 5 \\
\hline
\end{tabular}

TABLE III

IMPORTANT CONTRIBUTORS TO CNRS'S INTERNATIONALLY CO-AUTHORED PUBLICATIONS

\begin{tabular}{cccc}
\hline Year & $1991-1992$ & $1999-2000$ & $2007-2008$ \\
\hline $\begin{array}{c}\text { Total } \\
\text { international } \\
\text { co-authored } \\
\text { papers }\end{array}$ & & & \\
\hline
\end{tabular}

\begin{tabular}{ccccccc}
\hline $\begin{array}{c}\text { Collaborative } \\
\text { countries }\end{array}$ & $\begin{array}{c}\text { Share } \\
(\%)\end{array}$ & Rank & $\begin{array}{c}\text { Share } \\
(\%)\end{array}$ & Rank & $\begin{array}{c}\text { Share } \\
(\%)\end{array}$ & Rank \\
Germany & $10.34 \%$ & 5 & $15.09 \%$ & 2 & $18.41 \%$ & 1 \\
USA & $20.69 \%$ & 2 & $11.95 \%$ & 3 & $18.32 \%$ & 2 \\
Spain & & & $10.69 \%$ & 4 & $11.26 \%$ & 3 \\
UK & $31.03 \%$ & 1 & $10.06 \%$ & 5 & $10.12 \%$ & 4 \\
Italy & $17.24 \%$ & 3 & $18.87 \%$ & 1 & $9.86 \%$ & 5 \\
\hline
\end{tabular}

TABLE IV

IMPORTANT CONTRIBUTORS TO CSIC'S INTERNATIONALLY CO-AUTHORED PUBLICATIONS

\begin{tabular}{ccccccc}
\hline Year & \multicolumn{2}{c}{$1991-1992$} & \multicolumn{2}{c}{$1999-2000$} & $2007-2008$ \\
\hline $\begin{array}{c}\text { Total international } \\
\text { co-authored papers }\end{array}$ & \multicolumn{2}{c}{7} & \multicolumn{2}{c}{165} & \multicolumn{2}{c}{743} \\
\hline $\begin{array}{c}\text { Collaborative } \\
\text { countries }\end{array}$ & $\begin{array}{c}\text { Share } \\
(\%)\end{array}$ & Rank & $\begin{array}{c}\text { Share } \\
(\%)\end{array}$ & Rank & $\begin{array}{c}\text { Share } \\
(\%)\end{array}$ & Rank \\
USA & $42.86 \%$ & 2 & $14.55 \%$ & 3 & $19.52 \%$ & 1 \\
France & & & $28.48 \%$ & 1 & $18.71 \%$ & 2 \\
Germany & $28.57 \%$ & 3 & $13.33 \%$ & 4 & $15.21 \%$ & 3 \\
UK & $57.14 \%$ & 1 & $15.15 \%$ & 2 & $11.71 \%$ & 4 \\
Italy & & & $6.67 \%$ & 6 & $8.88 \%$ & 5 \\
\hline
\end{tabular}

TABLE V

IMPORTANT CONTRIBUTORS TO CNR'S INTERNATIONALLY CO-AUTHORED PUBLICATIONS

\begin{tabular}{lcccccc}
\hline Year & $1991-1992$ & $1999-2000$ & $2007-2008$ \\
\hline $\begin{array}{c}\text { Total } \\
\text { international } \\
\text { co-authored } \\
\text { papers }\end{array}$ & & & & & & \\
\hline $\begin{array}{c}\text { Collaborative } \\
\text { countries }\end{array}$ & $\begin{array}{c}\text { Share } \\
(\%)\end{array}$ & Rank & $\begin{array}{c}\text { Share } \\
(\%)\end{array}$ & Rank & $\begin{array}{c}\text { Share } \\
(\%)\end{array}$ & Rank \\
France & $30.00 \%$ & 1 & $18.12 \%$ & 2 & $22.80 \%$ & 1 \\
USA & $30.00 \%$ & 1 & $16.67 \%$ & 3 & $17.75 \%$ & 2 \\
Germany & $30.00 \%$ & 1 & $18.84 \%$ & 1 & $15.31 \%$ & 3 \\
Spain & $10.00 \%$ & 2 & $7.25 \%$ & 6 & $10.91 \%$ & 4 \\
UK & $10.00 \%$ & 2 & $12.32 \%$ & 4 & $10.75 \%$ & 5 \\
\hline
\end{tabular}

\section{CONCLUSION}

This paper is a pilot study of comparing the behaviors of five big MISOs in prolific countries - CAS in China, RAS in Russia, CNRS in France, CSIC in Spain, and CNR in Italy in the field of nanotechnology from the perspective of bibliometrics. The results show that nano R\&D activities in these organizations increased during the period from 1990 to 2009 . They all take an important role in their nation's nano R\&D. But RAS has salient position in Russian nano research in view of its high share of more than 50\%. Meanwhile, the impact (measured by aged citation) increase as well. In general, all the MISOs have considerable collaborative publications, but CAS is the less collaborative one at both the country level and the institute level. The discipline analysis shows chemistry and material sciences are the main subject categories in all the five MISOs, but each of them have their own foci. 
This paper gives a snapshot of the most important Multi-institute scientific organizations in nanotechnology, and provide for the researchers and policy-makers to monitor the development of nanotechnology from the perspective of institutions.

\section{ACKNOWLEDGMENT}

Many thanks to Alan L. Porter and Jan Youtie who are from Georgia Institute of Technology. They give me a lot of useful advices, suggestions and help during the paper composition.

\section{REFERENCES}

[1] M. Coccia, "A scientometric model for the assessment of scientific research performance within public institutes," Scientometrics, vol. 65, pp. 307-321, 2005.

[2] C. K. Lee, "A Scientometric study of the research performance of the Institute of molecular and cell biology in Singapore," Scientometrics, vol. 56, pp. 95110, 2003.

[3] P. Vinkler, "General performance indexes calculated for research institutes of the Hungarian Academy of Sciences based on scientometric indicators," Scientometrics, vol. 41, pp. 185-200, 1998.

[4] P. Vinkler, "Composite scientometric indicators for evaluating publication of research institutes," Scientometrics, vol. 68, pp. 629-642, 2006.

[5] Z. Hayati and S. Ebrahimy, "Correlation between quality and quantity in scientific production: A case study of Iranian organizations from 1997 to 2006," Scientometrics, vol. 80, pp. 625-636, 2009.

[6] E. Bassecoulard and M. Zitt, "Indicators in a research institute: A multi-level classification of scientific journals," Scientometrics, vol. 44, pp. 323-345, 1999.

[7] R. M. Yawson, et al., "Developing a performance measurement framework to enhance the impact orientation of the Food Research Institute, Ghana," $R$ \& D Management, vol. 36, pp. 161-172, Mar 2006.

[8] J. Hyvarinen, "Evaluation of Tekes funding for research institutes and universities - the role of talent," Research Evaluation, vol. 18, pp. 365-373, 2009.

[9] A. Modrego-Rico, et al., "Developing indicators to measure technology institutes' performance," Research Evaluation, vol. 14, pp. 177-184, 2005.

[10] G. Abramo, et al., "Research collaboration and productivity: is there correlation?," Higher Education, vol. 57, pp. 155-171, Feb 2009.

[11] J. C. Guan, et al., "Collaboration between industry and research institutes/universities on industrial innovation in Beijing, China," Technology Analysis \& Strategic Management, vol. 17, pp. 339-353, Sep 2005.

[12] Y. G. Lee, "Patent licensability and life: registered by South Korean public research institutes," Scientometrics, vol. 75, pp. 463-471, 2008.

[13] J. C. Guan and Y. He, "Comparison and evaluation of domestic and international outputs in Information Science \& Technology research of China," Scientometrics, vol. 65, pp. 215-244, Nov 2005.

[14] D. H. Lee, et al., "Performance and adaptive roles of the government-supported-research-institute in southkorea," World Development, vol. 19, pp. 1421-1440, Oct 1991.
[15] A. J. Nederhof and E. Van Wijk, "Profiling institutes: identifying high research performance and social relevance in the social and behavioral sciences," Scientometrics, vol. 44, pp. 487-506, 1999.

[16] B. Thijs and W. Glanzel, "A structural analysis of benchmarks on different bibliometrical indicators for European research institutes based on their research profile," Scientometrics, vol. 79, pp. 377-388, 2009.

[17] B. Thijs and W. Glanzel, "A structural analysis of collaboration between European research institutes," Research Evaluation, vol. 19, pp. 55-65, Mar 2010.

[18] B. Thijs, et al., "Israeli research institutes: a dynamic and evaluative perspective," Research Evaluation, vol. 18, pp. 251-260, Sep 2009.

[19] B. Thijs and W. Glanzel, "A structural analysis of publication profiles for the classification of European research institutes," Scientometrics, vol. 74, pp. 223236, 2008.

[20] A. L. Porter, et al., "Refining search terms for nanotechnology," Journal of Nanoparticle Research, vol. 10, pp. 715-728, May 2008.

[21] J. Youtie, et al., "Assessing the Nature of Nanotechnology: Can We Uncover an Emerging General Purpose Technology?," Journal of Technology Transfer, vol. 33, pp. 315-329 2008

[22] J. Youtie, et al., "Nanotechnology publications and citations by leading countries and blocs," Journal of Nanoparticle Research, vol. 10, pp. 981-986, Aug 2008.

[23] Z. Huang, et al., "International nanotechnology development in 2003: Country, institution, and technology field analysis based on USPTO patent database," Journal of Nanoparticle Research, vol. 6, pp. 325-354, Aug 2004.

[24] A. Hullmann and M. Meyer, "Publications and patents in nanotechnology - An overview of previous studies and the state of the art," Scientometrics, vol. 58, pp. 507527, 2003.

[25] M. S. M. Alencar, et al., "Nanopatenting patterns raise issues for managers, countries," Research-Technology Management, vol. 49, pp. 8-9, Jul-Aug 2006.

[26] A. Hullmann, "Measuring and assessing the development of nanotechnology," Scientometrics, vol. 70, pp. 739-758, Mar 2007.

[27] X. Liu, et al., "Trends for nanotechnology development in China, Russia, and India," Journal of Nanoparticle Research, vol. 11, pp. 1845-1866, Nov 2009.

[28] I. Rafols, "Strategies for knowledge acquisition in bionanotechnology - Why are interdisciplinary practices less widespread than expected?," Innovationthe European Journal of Social Science Research, vol. 20, pp. 395-412, Dec 2007.

[29] Y. Takeda, et al., "Nanobiotechnology as an emerging research domain from nanotechnology: A bibliometric approach," Scientometrics, vol. 80, pp. 23-38, Jul 2009.

[30] Y. Guo, et al., "The research profiling method applied to nano-enhanced, thin-film solar cells," $R$ \& $D$ Management, vol. 40, pp. 195-208, Mar 2010.

[31] A. Pouris, "Nanoscale research in South Africa: A mapping exercise based on scientometrics," Scientometrics, vol. 70, pp. 541-553, Mar 2007.

[32] R. K. Sastry, et al., "Integrating nanotechnology into agrifood systems research in India: A conceptual framework," Technological Forecasting and Social Change, vol. 77, pp. 639-648, 2010. 
[33] Y. Nakagawa, et al., "Assessment of social implications of nanotechnologies in Japan: Application of problem structuring method based on interview surveys and cognitive maps," Technological Forecasting and Social Change, vol. 77, pp. 615-638, 2010.

[34] L. Kay and P. Shapira, "Developing nanotechnology in Latin America," Journal of Nanoparticle Research, vol. 11, pp. 259-278, Feb 2009.

[35] A. L. Porter and J. Youtie, "How interdisciplinary is nanotechnology?," Journal of Nanoparticle Research, vol. 11, pp. 1023-1041, Jul 2009.

[36] M. Meyer and O. Persson, "Nanotechnology Interdisciplinarity, patterns of collaboration and differences in application," Scientometrics, vol. 42, pp. 195-205, Jun 1998.

[37] I. Rafols and M. Meyer, "Diversity and network coherence as indicators of interdisciplinarity: case studies in bionanoscience," Scientometrics, vol. 82, pp. 263-287, Feb 2010.

[38] J. Schummer, "Multidisciplinarity, interdisciplinarity, and patterns of research collaboration in nanoscience and nanotechnology," Scientometrics, vol. 59, pp. 425-465, 2004.

[39] A. L. Porter and J. Youtie, "Where does nanotechnology belong in the map of science?," Nature Nanotechnology, vol. 4, pp. 534-536, Sep 2009.

[40] T. Heinze, et al., "Identifying creative research accomplishments: Methodology and results for nanotechnology and human genetics," Scientometrics, vol. 70, pp. 125-152, Jan 2007.

[41] M. Meyer, "Knowledge integrators or weak links? An exploratory comparison of patenting researchers with their non-inventing peers in nano-science and technology," Scientometrics, vol. 68, pp. 545-560, Dec 2006.

[42] M. Meyer, "Are patenting scientists the better scholars? An exploratory comparison of inventor-authors with their non-inventing peers in nano-science and technology," Research Policy, vol. 35, pp. 1646-1662, Dec 2006.

[43] T. Braun, et al., "Nanoscience and nanotechnology on the balance," Scientometrics, vol. 38, pp. 321-325, Feb 1997.

[44] S. Bass and L. Kurgan, "Discovery of factors influencing patent value based on machine learning in patents in the field of nanotechnology," Scientometrics, vol. 82, pp. 217-241, 2010.

[45] L. Huang, et al., "Identifying the Emerging Roles of Nanoparticles in Biosensors," Journal of Business Chemistry, vol. 7, 2010.

[46] L. Leydesdorff, "Can scientific journals be classified in terms of aggregated journal-journal citation relations using the Journal Citation Reports?," Journal of the American Society for Information Science and Technology, vol. 57, pp. 601-613, 2006.

[47] J. S. Katz and B. R. Martin, "What is research collaboration?," Research Policy, vol. 26, pp. 1-18, 1997.

[48] M. Smith, "The trend toward multiple authorship in psychology," American Psychologist, vol. 13, pp. 596599,1958

[49] K. Subramanyam, "Bibliometric studies of research collaboration - a review," Journal of Information Science, vol. 6, pp. 33-38, 1983. 